\title{
CARTOGRAFIA DA ALEGRIA: ENCONTROS ENTRE PALHAÇARIA E PSICODRAMA
}

\author{
Marília Meneghetti Bruhn ${ }^{1, *}$ [D
}

\section{RESUMO}

Este escrito propõe-se a compartilhar encontros alegres entre a arte da Palhaçaria e a abordagem sociopsicodramática. A metodologia adotada foi a cartografia, para acompanhar o processo experienciado no Grupo de Estudos e Práticas em Psicologia, palhaçaria e Psicodrama (GEP). Durante os anos de 2017 e 2018, o GEP promoveu encontros mensais durante 12 meses, nos quais se estudaram e vivenciaram princípios dessas duas abordagens inspiradas nas artes cênicas. Nos relatos do diário de campo produzidos com o GEP, destacaram-se o conceito moreniano de espontaneidade-criatividade e a lógica da alegria presente na arte da palhaçaria. Por fim, concluiu-se que a palhaçaria e o psicodrama são abordagens que oferecem ferramentas para atingir objetivos existenciais em comum.

PALAVRAS-CHAVE: Palhaçaria; Psicodrama; Clown; Cartografia.

\section{CARTOGRAPHY OF JOY: MEETINGS BETWEEN CLOWNS AND PSYCHODRAMA}

\begin{abstract}
This writing proposes to share joyful encounters between the art of clowning and the sociopsychodramatic approach. The methodology adopted was cartography to accompany the process experienced in the Group of Studies and Practices in Psychology, Clowning, and Psychodrama (GEP). During the years 2017 and 2018, the GEP held monthly meetings for twelve months in which they studied and experienced the principles of these two approaches inspired by the performing arts. In the field diary reports produced with GEP, the morenian concept of spontaneity-creativity and the logic of joy present in the art of clowning stood out. Finally, the conclusion is that clowning and psychodrama are approaches that offer tools to achieve common existential goals.
\end{abstract}

KEYWORDS: Clowning; Psychodrama; Clown; Cartography.

\section{CARTOGRAFÍA DE LA ALEGRÍA: ENCUENTROS ENTRE PAYASOS Y PSICODRAMA}

\begin{abstract}
RESUMEN
Este escrito propone compartir encuentros alegres entre el arte del payasaria y el enfoque sociopsicodramático. La metodología adoptada fue la cartografía para acompanhar el proceso vivido en el Grupo de Estudios y Prácticasen Psicología, Payasaria y Psicodrama (GEP). Durante losaños 2017 y 2018, la GEP realizo reuniones mensuales durante doce meses em las que estudiaron y vivieron los principios de estos dos enfoques inspirados em las artes escénicas. Em los diarios de campo elaborados con GEP se destaco el concepto moreniano de espontaneidad-creatividad y la lógica de la alegría presente em el arte de payasaria. Finalmente, se concluyó que payasaria y psicodrama son enfoques que ofrecen herramientas para lograr metas existenciales comunes.
\end{abstract}

PALABRAS CLAVE: Payasaria; Psicodrama; Payaso; Cartografía.

1.Universidade Federal do Rio Grande do Sul - Programa de Pós-Graduação em Psicologia Institucional - Porto Alegre (RS), Brasil. *Autora correspondente: marilia_bruhn@hotmail.com

Editora de seção: Leila Kim

Recebido: 21 Fev 2021 | Aceito: 13 Jun 2021 


\section{INTRODUÇÃO}

"Aqui jaz um homem que abriu as portas da alegria à psiquiatria" é o epitáfio que Jacob Levy Moreno, criador do psicodrama, desejou para o seu túmulo. Quando soube disso, ao ler no livro Psicologia do encontro, de Eugênio Garrido Martín (1996), tive certeza da escolha de me tornar psicodramatista. As experiências mais transformadoras e terapêuticas que vivenciei foram alegres; por isso, desde o início do meu percurso na psicologia, busquei abordagens que focassem as potências dos seres humanos, em vez do trauma, a doença, a tristeza e o sofrimento.

Em 2017, encontros inesperados com uma palhaça psicóloga mostraram-me outras possibilidades para uma psicologia com alegria - a palhaçaria ${ }^{1}$. A palhaça Dulcinóia apareceu em uma reunião de psicodramatistas e propôs um jogo inusitado: “e se fizermos uma corrida e ganha quem chegar por último?”. Olho para Dulcinóia e vejo ela se esforçando ao máximo para correr o mais devagar possível, em câmera lenta. Como não rir dessa figura compenetrada de nariz vermelho?

Esta palhaçaria é o oposto dos estereótipos de palhaço — homem branco com boca vermelha e sapatos grandes -, os quais repetem exaustivamente as mesmas gags $^{2}$ na televisão, no teatro ou em espetáculos de circo. Dulcinóia me apresentou uma palhaçaria que é "a arte do encontro, coconstruída no improviso, assim como o Psicodrama.É uma palhaçaria marcada pelo signo do humor, do riso com o outro, ao invés do riso sobre o outro" (Bruhn et al., 2019, p. 69). O humor do palhacear é baseado em uma transgressão do status quo, ou seja, em uma desconstrução da conserva cultural.

Inspirada pela Dulcinóia - e por todas outras palhaças que se relacionam comigo -, neste escrito, tenho como objetivo tecer aproximações entre a socionomia e a palhaçaria a partir do conceito moreniano de espontaneidade-criatividade e da lógica da alegria presente no palhacear. Este artigo é parte de uma pesquisa mais ampla realizada para o Trabalho de Conclusão de Especialização em Sociopsicodrama nível 1, no qual trabalhei com o seguinte problema: "como o psicodrama e a palhaçaria podem produzir aproximações que potencializam as práticas da Psicologia?” (Bruhn, 2019, p. 10).

\section{PERCURSO METODOLÓGICO}

Como referência metodológica para esta pesquisa, inspiro-me na prática da cartografia proposta por Gilles Deleuze e Félix Guattari (1995). Os autores têm como proposta pensar uma pesquisa para além dos discursos científicos hegemônicos, valorizando o que se passa nos intervalos e interstícios. Os principais aspectos da cartografia permitem composições com a socionomia e a palhaçaria: busca-se tratar as pessoas pesquisadas como seres relacionais ao invés de objetos inertes de pesquisa, procura-se integrar pensamento, emoção e corpo durante o relato do cartógrafo e valoriza-se o acompanhamento de um processo em movimento durante o ato de pesquisar. Devido às possibilidades de agenciamentos entre psicodrama e a palhaçaria com a cartografia, escolhi seguir este percurso metodológico cartográfico. Mas, afinal, como fazer uma cartografia?

Deleuze e Guattari (1995) retiram o termo cartografia das ciências geográficas para empregá-lo para campos da filosofia, política e subjetividade. A cartografia é o exercício de pesquisar no encontro. Assim, tanto a pesquisadora quanto quem é pesquisado também afetam e são afetados por esses encontros. Luciano Bedin da Costa (2014) ressalta que o cartógrafo pode ser entendido como um criador de realidade, um compositor, "aquele que com/põe na medida em que cartografa" (p. 70).

A cartografia pode ser melhor descrita não como um método, mas como uma reversão do método. Como assim? Explico: a etimologia da palavra método (metá-hódos) — refere-se a um caminho (hódos) determinado pelas metas (metâ), as quais são estabelecidas para que o próprio caminhar seja feito. Virginia Kastrup, Eduardo Passos e Liliana Escóssia afirmam que “a cartografia propõe uma reversão metodológica: transformar o metá-hódos em hódos-meta” (2009, p. 11). O percurso metodológico vai se construindo durante a prática da pesquisa. "O pesquisador-cartógrafo não sabe, de antemão, o que irá lhe atravessar, quais serão os encontros que irá ter e no que estes mesmos encontros poderão acarretar” (Costa, 2014, p. 70). Cartografar é estar disponível para os encontros — profundas relações eu-tu — que poderão ocorrer ao acaso, sendo

1.Optei por utilizar o termo palhaçaria porque quero dar visibilidade ao trabalho com palhaças e palhaços desenvolvidos no Brasil, ao invés de ressaltar e reproduzir a visão eurocentrada contida na expressão clown.

2.Piadas ou cenas prontas que são ensaiadas e repetidas.

3.Neologismo utilizado informalmente por palhaços que significa o ato de fazer palhaçadas. 
imprevisível o que vai acontecer no caminho de uma pesquisa. Assim, cartografar é acompanhar processos que estão em movimento, permeados por encontros, em um território.

Neste escrito, o território, o campo de pesquisa é o Grupo de Estudos e Práticas em Psicologia, Palhaçaria e Psicodrama (GEP), que ocorria mensalmente em Porto Alegre e reunia pessoas interessadas em compor aproximações entre essas três áreas de conhecimento. Para registrar este percurso metodológico, utilizei um diário de campo no qual — através da escrita - foram registrados sentimentos, pensamentos e reflexões ocorridos durante e após os encontros no GEP. Os relatos compartilhados nos diários de campo e utilizados para compor este artigo não têm como objetivo apresentar uma verdade única e neutra do que acontece no GEP. O intuito de uma cartografia é acompanhar um processo considerando os afetos que perpassam a mim e todos os participantes do nosso grupo. Assim, mais importante do que a literalidade dos relatos da experiência é o que a história produz e como isso nos afeta. Quanto ao sigilo e a questões éticas, é importante ressaltar que os participantes do GEP eram informados da produção de pesquisas durante os encontros dos grupos e da possibilidade de acontecimentos no grupo servirem de inspiração para a escrita de diários de campos. No diário de campo, escrevo sobre minhas implicações, afetações e análises do percurso de pesquisar o GEP. Nos próximos subcapítulos, abordo as concepções de espontaneidade-criatividade e de alegria, exemplificando com relatos do diário, os quais são indicados com recuo e itálico.

\section{ESPONTANEIDADE-CRIATIVIDADE}

Estávamos sentados no chão em um círculo, quando a participante L. do GEP perguntou se ser espontâneo é fazer "apenas o que tiver vontade". Ela não conhecia o psicodrama, mas gostava muito de palhaçaria. Respondi para o grupo:

- Então, preciso fazer uma confissão: a primeira vez que ouvi falar que o Moreno trabalhava com espontaneidade, achei ele louco e sem noção. A ideia que eu tinha de uma pessoa espontânea era bem diferente da que eu tenho hoje. Quando eu era adolescente, uns parentes alemães vieram nos visitar depois da queda do Muro de Berlim. Há décadas não falávamos com eles, mas minha família no Brasil os recebeu com muito afeto. Enquanto preparávamos o churrasco de domingo, algumas crianças pequenas da familia tomavam banho na piscina com suas roupas de banho. De repente, sem avisar nada, "espontaneamente", meu tio alemão de 2 metros de altura caminha em direção à piscina, tira a roupa, ficando completamente nu, epula na água junto com as crianças. Lembro da cara de choque de toda a família brasileira. Depois do susto inicial, o adjetivo que mais usaram para descrevê-lo era "espontâneo".

Ouvi várias risadas e ri um pouco também; a história era engraçada. Depois, continuei falando:

- Assim, até começar a estudar Psicodrama, achava que espontaneidade era ser sem noção, fazer o que quiser na hora que quiser e sem se preocupar com a reação dos outros. No entanto, a espontaneidade moreniana é bem diferente do conceito do meu tio alemão pelado na piscina com crianças assustadas (Diário de Campo, 2017).

Mas, afinal, o que é espontaneidade? De acordo com Jacob Levy Moreno (1997), a palavra "espontâneo" em latim é sponte, que significa "por livre vontade". Moreno afirma que todo ser humano é um gênio em potencial, um agente espontâneo. "A espontaneidade é um estado de prontidão do sujeito para responder mais rapidamente quando lhe for solicitado. É uma condição — um ajustamento — do sujeito, uma preparação dele para uma ação livre" (Moreno, 1992, p. 152). A espontaneidade também é descrita como "a resposta adequada a uma nova situação ou uma nova resposta a uma situação antiga" (Moreno, 1984, p. 58). Essa espontaneidade, como toda visão de ser humano moreniana, precisa ser considerada pela perspectiva relacional. Ou seja, o sujeito é um ser social que se constrói na relação com o outro. Por exemplo, para sermos espontâneos, precisamos considerar o impacto das nossas ações nas interações sociais.

Para Moreno (1997), o nascimento é o momento em que o ser humano está mais espontâneo — e menos influenciado pela conserva cultural -, porque o bebê passa por uma situação totalmente nova, sem nenhum modelo anterior, em que precisa conquistar a sobrevivência. Para que a criança viva, são necessárias respostas rápidas e adequadas, segundo o estímulo 
do momento. José de Souza Fonseca Filho (1980) conclui que "cada indivíduo teria, então, uma matriz espontânea, a partir da qual se desenvolveria a sua personalidade" (p. 12).

O fator $e$ (fator espontaneidade) é um agente a favor da criança, que atua muito antes do desenvolvimento da memória e inteligência. Contudo, com o desenvolvimento infantil progressivo, a inteligência e a memória assumem a liderança e o fator $e$ é submetido à conserva cultural. O treino da espontaneidade, através do aquecimento, é a forma desenvolvida por Moreno para resgatar estados de espontaneidade que, por um momento, conseguem se expressar como uma "centelha

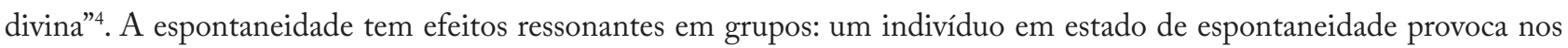
demais o mesmo tipo de resposta, proporcionando uma relação télica (Moreno, 1997).

Assim como a espontaneidade, a criatividade é um dos conceitos nucleares do psicodrama. Sua importância fica evidente no livro Quem sobreviverá? , no qual Moreno (1992) responde ao título afirmando que sobreviverá quem, em última instância, puder criar. A criatividade está presente em todos os seres vivos e é fundamental para garantir a sobrevivência. Nos livros de Moreno, frequentemente o autor refere-se à espontaneidade-criatividade como um conceito gemelar. Todavia, espontaneidade e criatividade não são sinônimas e podem existir separadamente (Fonseca Filho, 1980). Quando uma pessoa tem um alto grau de espontaneidade, mas não é criativa, ela é uma "idiota espontânea". Um exemplo para o "idiota espontâneo" é a qualidade dramática de um indivíduo que manifesta bastante fator $e$, mas não cria nada de novo: os atos repetitivos são experimentados como uma genuína autoexpressão (Moreno, 1997). Já “o extremo oposto de um homem que é um gênio da dramatização do eu, mas totalmente improdutivo, é o homem totalmente produtivo e criador, embora talvez seja inexpressivo e insignificante como indivíduo"(Moreno, 1997, p. 141). Portanto, no psicodrama busca-se estimular situações em que a espontaneidade-criatividade esteja concatenada no aqui-e-agora.

A espontaneidade ocorre quando as pessoas conseguem viver, no tempo presente, uma relação livre de transferências ou de interferências dos climas afetivos negativos e inibidores. "A criatividade pertence à categoria da substância, substância primeira. Para ser efetiva necessita de um catalisador. O catalisador da criatividade é a espontaneidade” (Fonseca Filho, 1980, p. 14). Segundo Fonseca Filho (1980), o produto da criatividade sem o momento espontâneo acaba por se tornar uma conserva cultural. Por exemplo, uma obra de arte em um museu é um quadro produzido pela criatividade, mas que faz parte da conserva porque é um produto finalizado do processo criador. $\mathrm{O}$ momento da criação no qual estava sendo pintado o quadro - em que há espontaneidade-criatividade — é valioso por ser uma expressão da “centelha divina” (Moreno, 1992). Contudo, é importante salientar que "a espontaneidade e a conserva cultural não existem em forma pura: uma é função, é parasita da outra" (Moreno, 1997, p. 156). Assim, "não pode ser realizada a espontaneidade absoluta nem a conserva absoluta, mas comprovou-se que são princípios heurísticos únicos” (Moreno, 1997, p. 464). Sobre esses princípios morenianos da espontaneidade-criatividade e conserva cultural e o impacto no psicodrama e na palhaçaria, tivemos uma conversa no GEP que foi registrada no trecho do diário de campo a seguir:

- Nossa, espontaneidade-criatividade está muito relacionada com a palhaçaria! - fala a participante L. - As açôes do palhaço têm que ser adequadas com o contexto e o público com o qual ele está se relacionando... Tem alguns palhaços que são "idiotas espontâneos", fazem sempre a mesma gague, mas como se fossem a primeira vez que estivessem vivendo essa cena. São engraçados, mas só se você os assistir uma única vez. Já outros palhaços são criativos, vivem criando esquetes novas, mas não conseguem se conectar com as pessoas e com as emoçôes.

- É mesmo! - concorda a participante B. - O pior são os clowns que não são nem criativos e nem espontâneos. Como aqueles "palhaços" contratados para festas infantis que sempre repetem a mesma cena da peruca que fica arrepiada e ninguém ri. Parece que nem ele acredita no que está sendo e no que está fazendo.

- Por isso que tanta gente não gosta de palhaços... Acham que a arte da palhaçaria é ser esses personagens falsos. Se sentem enganados... - comenta a participante J.

4. Jacob Levy Moreno (1997) propôs uma visão ontológica na qual o ser humano possui uma "centelha divina”, ou seja, uma dimensão do Deus-criador que possibilita uma potência de criar atrelada ao estado de espontaneidade. 
- Ai é que esta... A palhaça não tem que fingir que é palhaça. Eu sou palbaça tanto quanto eu sou L. (nome da participante). Ser clown não é ser um personagem; ser palhaço é ser você com a máxima intensidade. Todas as pessoas podem ser palhaças; só precisam se "exercitar" para tornar este papel forte.

- O que eu mais gosto em ser palhaça é que as minhas fraquezas e erros se tornam potência. - fala a participante $R$. - Por exemplo, sou muito desajeitada e, quando estou no meu estado de palhaça, exagero o máximo possível isso. Ou seja, o que era fraqueza - ser desajeitada — se torna minha potência como palhaça: todos riem comigo das minhas atrapalhações.

- Como psicóloga - relata a participante E. - estava pensando o quanto a palbaçaria pode ser terapêutica tanto para a plateia que ri e se vê na cena quanto para o palhaço, que consegue se conhecer ainda mais quando usa o nariz vermelho. Uma vez, escutei que "o nariz vermelho é a menor máscara do mundo, a que menos esconde e a que mais revela", ou seja, é o objeto intermediário perfeito.

-O que é objeto intermediário? - interroga $R$.

- No Psicodrama, objeto intermediário é qualquer objeto que facilite o contato entre duas ou mais pessoas. O objeto intermediário pode facilitar o "aquecimento" em um sociodrama, liberando a espontaneidade-criatividade dos participantes. - explica E.

- Por falar em aquecimento, na palhaçaria nós também fazendo jogos para se aquecer e colocar o nariz vermelho. comenta a participante L. - Os aquecimentos tem o objetivo de nos colocar em movimento no aqui-e-agora.

— Palhaço é alegria assim como Psicodrama é espontaneidade! — afirma R. (Diário de Campo, 2017).

\section{ALEGRIA}

A espontaneidade-criatividade no psicodrama tem o mesmo destaque que a alegria tem na palhaçaria. $O$ trecho a seguir, do diário de campo, auxiliará na compreensão do conceito de alegria utilizado no presente artigo:

- A principal lógica de vida do Palhaço é a alegria. - afirma a participante $R$.

- A alegria como uma emoşão? Como fazer rir? - pergunto eu.

- A alegria é uma emoção básica que tem como objetivo nos motivar para a ação, fazendo as pessoas agirem para que se repitam experiências prazerosas... - descreve E.

- Fazer rir é importante, mas a alegria é muito mais do que uma emoção... É uma potência política. - responde $R$. (Diário de Campo, 2018).

Para Kátia Maria Kasper (2004), a alegria é mais do que uma emoção, podendo ser entendida como uma força política. Gilles Deleuze (2002) se inspira no filósofo Espinosa para pensar a alegria e a tristeza. Para esse autor, a alegria são afetos que podem aumentar a nossa capacidade de agir e ser. Já a tristeza diminui a nossa capacidade de agir e deteriora as nossas relações. Assim, a proposta da palhaçaria é ampliar os afetos alegres que promovem encontros, movimentos e mais possibilidades de existências (Kasper, 2004). 
Em Baruch Espinosa (2009), há uma filosofia da vida que busca denunciar tudo o que nos afasta das intensidades de viver, como valores transcendentes que se orientam contra a vida. "A vida está envenenada pelas categorias do Bem e do Mal, da falta e do mérito, do pecado e da remissão. O que perverte a vida é o ódio, inclusive o ódio contra si mesmo, a culpabilidade" (Deleuze, 2002, p. 32). Espinosa segue passo a passo denunciando as paixões tristes que existem em sentimentos como a tristeza, o ódio, a aversão, a zombaria, o desespero, a piedade, a indignação, a inveja, a humildade, o arrependimento, a abjeção, a vergonha, o pesar, a cólera, a vingança, a crueldade e, até mesmo, a esperança e a segurança. Ele critica "as falsificações da vida, todos os valores em nome dos quais nós depreciamos a vida: nós não vivemos, mantemos apenas uma aparência de vida, pensamos apenas em evitar a morte e toda a nossa vida é um culto à morte” (Deleuze, 2002, p. 32).

As críticas espinosistas às paixões tristes estão baseadas na teoria das afecções, segundo a qual todo o corpo tem certo grau de potência que pode afetar e ser afetado. As afecções são este encontro pontual de um corpo com o outro. Quando um corpo sofre afecções, quando ele é afetado por outro corpo, ocorre uma mudança, uma alteração que pode diminuir ou aumentar a sua potência. A partir dessas afecções, acontecem os afetos, uma experiência vivida, uma passagem. "Por afeto compreendo as afecções do corpo, pelas quais sua potência de agir é aumentada ou diminuída” (Espinosa, 2009, p. 100). Diferentemente das afecções instantâneas — se passam no presente —, os afetos têm um passado e envolvem uma capacidade futura de agir sobre o mundo. Por exemplo, uma afecção pode ser o momento pontual em que um espinho entra no meu dedo. A partir dessa afeç̧ão, vai operar uma variação em mim na potência de agir, que é o afeto. "Há, portanto, transições, passagens vivenciadas, durações mediantes as quais passamos para uma afecção maior ou menor. [...] Essas durações ou variações contínuas de perfeição são chamadas 'afetos'” (Deleuze, 2002, p. 55).

Para Espinosa (2009), os afetos se dividem em dois: os alegres e os tristes. Um encontro em que as relações podem se compor e aumentam a potência de agir se caracteriza pela ocorrência de um afeto de alegria. Para isso, é preciso que encontremos um corpo que combina com o nosso, que possui propriedades que se compõem com a nossas. Por exemplo, um abraço de um amigo quando nos sentimos sozinhos ou um beijo de quem amamos. Espinosa chama essas experiências de bons encontros, porque são momentos em que nos aproximamos mais do mundo, de outras pessoas e de nós próprios, amplificando nossa potência de afetar e ser afetado.Já os afetos tristes diminuem nossa potência de agir, de existir e de afetar e ser afetado. Um exemplo é quando somos agredidos por uma pessoa desagradável. As afecções à base de tristeza, quando nos atingem, vão se encadeando umas nas outras, diminuindo nosso poder de agir progressivamente (Trindade, 2019).

Segundo Espinoza (2009), dos afetos primários — alegria e tristeza — nascem todos os outros afetos, como o amor e o ódio. Os bons e os maus encontros não dependem apenas da nossa capacidade pessoal, mas também de quais encontros são possíveis na sociedade em que vivemos. Nesse sentido, os afetos também têm um aspecto político (Kasper, 2004).

A filosofia espinosista afirma que podemos ser ativos ou passivos nas causas dos afetos. As paixões ou os afetos passivos ocorrem quando não somos a principal causa dos nossos afetos, sendo afetados por outros corpos. As paixões podem ser alegres ou tristes. São afetos inconstantes, como um espinho que pode, repentinamente, machucar nosso pé (Trindade, 2019). Já os afetos ativos ou as ações são sempre alegres, porque Espinosa (2009) — assim como os humanistas — defende que o corpo se esforça constantemente para aumentar sua potência de agir. O corpo age por sua própria natureza, sempre buscando o crescimento e mais afetos alegres. Em uma conversa no GEP, descrita no diário de campo, podemos relacionar os conceitos de afeto, de potência e de drama (ação):

— Minha mãe disse que psicodrama vai combinar comigo porque sou sempre "dramática". Sou muito emotiva... comenta a participante $F$.

— Sabe o que significa "drama" para o psicodrama? Drama significa ação. — falo eu.

- Mais uma aproximação entre psicodrama e palhaçaria! Psicodrama significa investigação da alma humana através da ação. A alegria da palhaçaria é a busca pelas ações que façam aumentar nossa potência de agir. Ambos, palhaçaria e psicodrama, buscam o movimento, a ação! - afirma a participante K. (Diário de Campo, 2018). 
A Ética de Espinosa (2009) busca, então, como evitar a tristeza através da produção de paixões alegres e, posteriormente, ações alegres. Dependendo da cultura e da sociedade em que vivemos, criar afetos alegres se torna um desafio. Entretanto, Espinosa defende que todos podemos transformar os afetos passivos em afetos ativos, saindo da servidão para a liberdade de existir. Uma existência passiva, que apenas reage às paixões, pode-se transformar em uma existência marcada pela atividade e pela ação em direção à intensidade e multiplicidade de modos de agir.

Mas, como aumentar nossa potência de existir 5 ? Segundo Espinosa (2009), os afetos passivos alegres — paixões alegres — são bons encontros que aumentam nossa potência corporal ${ }^{6}$, gerando mais entendimento sobre o mundo, ou seja, produção de noções comuns. Essas noções comuns possibilitam uma compreensão mais ampla das nossas relações e possibilitam que consigamos escolher ativamente melhor os nossos encontros, tornando-nos ativos na geração de afetos.

Este poder de afetar e ser afetado, de cada corpo, não tem como ser conhecido previamente. A partir de experiências e composições é que vamos conhecendo do que um corpo é capaz e quais encontros potencializam nosso poder de ser afetado e de agir. Nesse sentido, a alegria é vista como uma potência política ${ }^{7}$, não necessariamente por fazer rir, mas por nos colocar em movimento (Kasper, 2004).

Considerando a teoria das afecções para Espinosa, o "corpo clownesco" - o palhaço — é pura alegria: "porque ele não pode parar o movimento de ser afetado e de agir" (Kasper, 2004, p. 32). Entretanto, é importante destacar que esse movimento de afetos não significa que o palhaço deve estar se movendo fisicamente o tempo todo. "Às vezes, suas paradas em cena são momentos gloriosos de um clown. O movimento que ele não pode parar é o de ser afetado e o de agir” (Kasper, 2004, p. 32). O trecho do Diário de Campo abaixo relaciona as concepções de movimento, palhaçaria e potência:

- Lembrei de uma frase sobre movimento, alegria e potência politica... Rosa Luxemburgo diz que "quem não se movimenta, não sente as correntes que o prende". - comenta a participante $L$.

- Isso faz todo o sentido quando pensamos que a palhaçaria faz uma denúncia sobre as operaçôes de poder, que envolvem separar os sujeitos daquilo que eles podem, separar o ser humano de sua potência. - eu falo (Diário de Campo, 2018).

O poder captura a nossa potência a partir de paixões tristes que nos tornam escravos e, às vezes, nos fazem querer ser escravizados. Os afetos de tristeza utilizados pelo poder nos paralisam, sequestrando a nossa liberdade de agir. A palhaçaria, nesse sentido, também é política, assim como a filosofia espinosista, e tem um compromisso de nos libertar de julgamentos e paixões tristes (Kasper, 2004).

\section{CONSIDERAÇÕES IN(FINITAS)}

De tudo, ficaram três coisas: a certeza de que [...] estava sempre começando, a certeza de que é preciso continuar e a certeza de que seria interrompido antes de terminar. Fazer da interrupção um caminho novo. Fazer da queda um passo de dança, do medo uma escada, do sono uma ponte, da procura um encontro (Sabino, 1956, p. 154).

As aproximações teóricas, filosóficas e práticas entre psicodrama e palhaçaria são tão recentes nas produções acadêmicas e na minha experiência como psicodramatista, que é um desafio tecer uma conclusão para este trabalho. Considerando o objetivo principal deste escrito psicodramático, que é o de propor aproximações entre psicodrama e palhaçaria que potencializam as intervenções em psicologia, a presente cartografia acompanhou um processo de início — começo — de

5. Para Espinosa (2009), potência de existir é sinônimo de potência de ser afetado.

6.Katia Maria Kasper (2004) utiliza a expressão "potência corporal" em sua tese para abordar as potências de existir que afetam um corpo. Neste contexto, um corpo "é constituído de relações internas entre seus órgãos, de relações externas com outros corpos e de afecções, isto é, da capacidade de afetar outros corpos e ser por eles afetado sem se destruir, regenerando-se com eles e os regenerando"(Chauí, 2010, s/p).

7. "Potência política" é uma expressão utilizada por Kasper (2004) para falar da potência do palhaço de colocar em movimento e afetar quem ou o que se relaciona com o clown.

8. "Corpo clownesco" é a expressão criada por Kasper (2004) para se referir ao palhaço enquanto um corpo que pode afetar e ser afetado de acordo com os princípios espinosistas. 
composições entre esses universos a partir da experiência de criação e desenvolvimento do GEP. Assim, seguindo pressupostos fenomenológico-existenciais, procurei relacionar os conceitos da abordagem psicodramática e do clown retratados nesta monografia a experiências, afetos e pessoas que participaram deste processo, evitando dissociá-los da construção do aprendizado como o uso do diário de campo.

A ideia é que esse escrito não seja uma conserva cultural que se encerre em si mesma, mas que possa servir de inspiração para novas criações e possíveis, tanto no meu percurso como psicodramatista quanto na trajetória das pessoas que se interessam por palhaçaria e socionomia. A partir da leitura sobre lógicas de vida do clown e das intensas experiências dos jogos de palhaçaria, percebi como o conceito de alegria (foco da palhaçaria) e conceito de espontaneidade-criatividade (ênfase do Psicodrama) permitem composições potentes. Para Espinosa (2009), a alegria são os afetos que expandem nossa capacidade de agir e ser, assim como, para Moreno (1997), a espontaneidade-criatividade também tem o propósito de ampliar a nossa potência de agir. Ou seja, a palhaçaria e o psicodrama são abordagens que oferecem ferramentas para atingir objetivos existenciais em comum.

Neste artigo, foi possível apontar algumas aproximações iniciais entre filosofias, teorias e técnicas utilizadas na palhaçaria e na socionomia, principalmente relacionando o conceito de alegria com o conceito de espontaneidade-criatividade. No entanto, mais do que dar respostas e conclusões, este trabalho demonstrou mais questionamentos e possibilidades de investigação.

O psicodrama me ensinou a acreditar na saúde que há nas relações humanas, e a palhaçaria evidenciou que esse caminho pode ser ainda mais alegre do que eu imaginava quando iniciei minha formação como psicodramatista. Assim, a palhaçaria me mostrou que o psicodrama não precisa ser só tragédia, mas também comédia. Se Moreno (1997) já dizia que uma resposta incita muitas outras perguntas, e não uma conclusão, esta aproximação entre palhaçaria e psicodrama segue as indicações do criador da Socionomia. Este escrito multiplica de forma psicodramática os questionamentos, baseando o aprendizado na problematização, dúvida, reflexão, considerações (in)finitas - e não em um ponto final.

\section{DISPONIBILIDADE DE DADOS DE PESQUISA}

Dados serão enviados mediante solicitação.

\section{FINANCIAMENTO}

Não se aplica.

\section{AGRADECIMENTOS}

Agradeço ao Grupo de Estudos e Práticas em Psicologia, Palhaçaria e Psicodrama (GEP), especialmente às coordenadoras Kim Ouakil Boscolo e Rita Barboza. Também agradeço à professora Júlia Motta pela orientação do trabalho de conclusão de Especialização em Psicodrama, do qual deriva o presente artigo.

\section{REFERÊNCIAS}

Bruhn, M. M. Cartografia da alegria: Aproximações entre psicodrama e palhaçaria. [Monografia, Instituto de Desenvolvimento Humano - Centro Universitário Amparense]. http://idh.com.br/public/storage/image_editor/files/ mono_MariliaBruhn.pdf

Bruhn, M. M., Boscolo, K. O., Barboza, R. P., \& Cruz, L. R. (2019). Psicologia, palhaçaria e psicodrama: Construção coletiva de aprendizados e intervenções. Revista Brasileira de Psicodrama, 27(1), 65-74. https://dx.doi. org/10.15329/0104-5393.20190007

Chaú, M. (2010). Espinosa, uma subversão filosófica. Cult, 109. https://revistacult.uol.com.br/home/baruch-espinosa/

Costa, L. B. (2014). Cartografia: uma outra forma de pesquisar. Revista Digital do LAV, 7(2), 65-76. https://doi. org/10.5902/19837348 
Deleuze, G., \& Guattari, F. (1995). Mil platôs: Capitalismo e esquizofrenia. Ed. 34.

Deleuze, G. (2002). Espinosa, filosofia prática. Escuta.

Espinosa, B. (2009). Ética. Autêntica.

Fonseca Filho, J. S. (1980). Psicodrama da Loucura. Ágora.

Kasper, K. M. (2004). Experimentaçôes clownescas: Os palhaços e a criação de possibilidades de vida. [Tese de Doutorado, Faculdade de Educação da Universidade Estadual de Campinas]. http://repositorio.unicamp.br/jspui/handle/ REPOSIP/252779

Kastrup, V., Passos, E., \& Escóssia, L. (2009). Pistas do método da cartografia: Pesquisa-intervenção e produção de subjetividade. Sulina.

Martín, E. G. (1996). Psicologia do Encontro: J. L. Moreno. Ágora.

Moreno, J. L. (1984). O teatro da espontaneidade. Summus.

Moreno, J. L. (1992). As Palavras do Pai. Psy.

Moreno, J. L. (1997). Psicodrama. Cultrix.

Sabino, F. (1956). O Encontro Marcado. Record.

Trindade, R. (2014). Espinosa: Origem e Natureza dos Afetos. https://razaoinadequada.com/2014/07/15/espinosaorigem-e-natureza-dos-afetos/ 